\title{
Leonel Del Prado (2020)
}

La comunidad en las políticas de desarrollo social

\author{
Paraná, Argentina, Fundación La \\ Hendija. ISBN: 978-987- 4948-58-8. \\ Páginas 292.
}

Santiago Tafernaberry Cicimbra

Estudiante de la Licenciatura de Trabajo Social

(Universidad Nacional de la República, Uruguay)

Correo: santitafernaberry03@gmail.com 
Es un honor poder reseñar este texto que corresponde al conjunto de libros que Fundación La Hendija pone a disposición para la lectura, las producciones de les autores intentan que les estudiantes, profesionales, intelectuales y público en general puedan desarrollar una capacidad crítica, reflexiva y permite la problematización sobre temáticas que nos transversalizan por ser pertenecientes a esta realidad.

En esta ocasión, Leonel Del Prado, nos invita a pensar, conocer y comprender el contexto actual de Argentina, dicho análisis lo realiza en el marco de su especialización denominada "Especialización en Abordaje Integral de Problemáticas Sociales en el Ámbito Comunitario" y dicho estudio es tomado como referencia para su tesis doctoral.

Para la elaboración de este texto utiliza la perspectiva de la Etnografía que es proveniente de la Antropología cultural-social, la cual se enfoca en comprender lo socio-cultural y tiene el objetivo de identificar y resignificar las prácticas culturales que llevan a diario la ciudadanía. La técnica utilizada por el autor fue principalmente la observación participante, a la vez, intenta ir más allá de esta técnica e incorpora otros insumos teóricos para comprender de una forma integral a la "comunidad" y al "desarrollo".

Tomando los aportes de Leonel Del Prado (2020) se puede mencionar que las políticas sociales intentan brindar respuestas para mejorar, cambiar una situación desfavorable y mejorar la calidad de vida de las personas. Por este motivo, el Ministerio se ha denominado de "Desarrollo Social".

Continuando, las políticas sociales tienen que adecuarse a los sucesivos cambios, transformaciones y a la complejidad de las sociedades con las cuales intervenimos, reconociendo las particularidades y diferencias de todas las personas para actuar acorde a esos aspectos. Por ende, el Estado como garante de los derechos humanos de la ciudadanía, debe unir esfuerzos y desafiarse para trabajar conjuntamente con la comunidad para generar desarrollo en el amplio sentido del concepto, donde todas las personas puedan impulsar sus libertades y dirigirse hacia la inclusión social.

El contenido del libro hace visible las posturas del autor sobre la multidimensionalidad de las políticas sociales que fueron impulsadas en el período 2003-2015 en la conducción de Alicia Kirchner en el Ministerio de Desarro- 
llo Social. Para ello, selecciona la experiencia o estudio de caso desarrollado en los Centros Integradores Comunitarios (CIC) de la Provincia de Entre Ríos (Argentina) para comprender la diversidad de posturas existentes sobre el aporte de los mismos y las acciones que impulsa con y para la comunidad.

El Ministerio de Desarrollo Social junto a los profesionales que se desempeñan en el mismo intentaron construir un nuevo discurso sobre las políticas sociales, donde las mismas ponen en tensión y cuestionan las políticas sociales impulsadas por el neoliberalismo. Concretamente, Leonel Del Prado nos muestra que estas nuevas políticas sociales no son focalizadas (periodo neoliberal) y mucho menos universales (Estado de Bienestar), buscaban dejar atrás las políticas del neoliberalismo.

Las nuevas políticas sociales fueron denominadas por Alicia Kirchner como "integrales", una idea superadora donde el Estado incentiva la participación social, por lo tanto, es importante tener en cuenta la visión de les ciudadanes que viven cotidianamente con distintas problemáticas, desde este sentido, darle voz, protagonismo e incentivar la toma de decisiones sobre asuntos que los afectan directamente o indirectamente, se visibiliza como fundamental a la hora de crear políticas sociales con la comunidad.

Materializando el concepto anteriormente mencionado, Leonel Del Prado (2020) entiende que los CIC favorecen a que la comunidad influya en las distintas instancias de la política: diagnóstico, planificación, ejecución y evaluación. En este sentido, los CIC buscan fortalecer el trabajo colectivo y articulado entre los distintos organismos del Estado, y las distintas profesiones, las organizaciones barriales se tienden a unificar, la sociedad civil se solidariza y genera sentido de pertenencia con sus propios pares, etc.

Para lograr lo mencionado, los CIC cuentan con líderes comunitares que son "actores claves de la comunidad que promueven la organización y la integración de la misma con el objetivo de lograr una plena ciudadanía social estimulando la participación” (Kirchner, 2010:59).

¿Cuáles fueron las transformaciones o cambios estructurales que aportaron la implementación de las nuevas políticas sociales en la comunidad? A partir de esta interrogante, Leonel Del Prado pretende guiar al lector en el cuestionamiento constante sobre las directrices que el Estado impulsa, el 
rol que ocupan los profesionales, la institución formadora de profesionales que trabajan con dichas políticas, la modificación del nuevo destinatario de políticas y el rol de la universidad como actor trascendental para generar alianzas y crear puentes con la comunidad.

Reconociendo las grandes brechas que pone de manifiesto el neoliberalismo, hay que pensar estrategias y procesos democratizadores que tengan como eje central la construcción de una comunidad en donde la ciudadanía pueda ejercer las libertades en las esferas políticas, económicas, sociales y culturales; y en el mismo sentido, que los actores sociales puedan revalorizar cómo las políticas sociales han modificado la cotidianidad de les profesionales y de aquelles destinataries que se encuentran inmersos en situaciones complejas y requieren de la respuesta de un Estado presente.

Leonel Del Prado hace visible la discusión entre políticas sociales y la forma que utiliza el gobierno para la disminución de las problemáticas sociales en el contexto que se encontraba Argentina en los periodos anteriores a la asunción de Alicia Kirchner. A través de la articulación entre Estado/ Desarrollo Social/Comunidad se pretende mitigar los efectos negativos que ha ocasionado el neoliberalismo (pobreza, exclusión social, desempleo, desigualdad social, concentración de la riqueza en pocas personas, violación de los derechos humanos, entre otros).

La discusión anteriormente mencionada, demuestra los desafíos que tienen las nuevas políticas sociales para satisfacer las necesidades de la población con la cual intervenimos y, por ende, al ser aplicadas en la sociedad, que su incidencia tenga resultados positivos.

Cada reflexión propuesta por el autor merecería un nuevo artículo para continuar debatiendo sobre las nuevas políticas sociales que intentamos poner en marcha para generar sociedades más democráticas. Ellas son: 1) el Estado construye a "la comunidad" como actor fundamental en la implementación cotidiana de la política de desarrollo social; 2) las políticas integrales son el medio para lograr la mentada "inclusión social"; 3 ) en el discurso oficial se denominaba "la participación de la comunidad en las políticas sociales" y la "democratización de las políticas sociales", donde, "los destinatarios de las políticas sociales son los "protagonistas"; 4) se puede 
constatar que muchos espacios se constituyen como lugares de disputas entre los diferentes actores.

En cada una de estas reflexiones, el autor no solo analiza el tema al que se enfoca, sino que intenta ampliar su mirada para pensar la relación entre Comunidad/Estado/Desarrollo. Donde en cada uno de los capítulos propuestos en este maravilloso libro, posicionan a les lectores en una difícil tarea de jerarquizar conocimientos, debido a que todas las premisas son sumamente enriquecedoras y necesarias para comprender cómo se deberían de ejecutar las nuevas políticas sociales para que el beneficio sea para toda la ciudadanía.

Se puede destacar que a lo largo del libro se hace hincapié en el papel que pueden aportar intelectuales y profesionales a la hora de generar e impulsar mecanismos y estrategias que tiendan a favorecer la creación de sociedades más justas, igualitarias, al fortalecimiento de redes, generar participación ciudadana, producir mayores oportunidades para los grupos minoritarios, y todos estos aspectos serán "aliados" para impulsar mayores procesos democráticos.

En función de ello, espero que estas reflexiones sean de utilidad para continuar profundizando y desarrollando nuevas contribuciones con el objetivo de pensar nuevas formas, significados y conceptualizaciones que les otorgamos a la comunidad, al desarrollo y a las políticas sociales, entendiendo que estos conceptos se encuentran entrelazados y articulados. Por lo tanto, los nuevos debates, cuestionamientos y problematizaciones en torno a la implementación de las nuevas políticas sociales deben de enfocarse en los resultados a los cuales se quiere llegar, es decir, la generación de procesos de inclusión social y de bienestar social.

En las reflexiones brindadas en "la comunidad en las políticas de desarrollo social" el autor dirige a les lectores hacia la formulación de nuevas preguntas para continuar indagando y pensando la relación entre Estado/ Comunidad/Desarrollo social. Las preguntas son: ¿De qué manera se puede fortalecer la relación entre las universidades y la comunidad? ¿Cuáles fueron los resultados que obtuvieron las nuevas políticas sociales implementadas en Argentina? ¿Cómo les profesionales del Ministerio de Desarrollo social pueden impulsar las nuevas políticas sociales sin que los nuevos gobiernos 
sean un impedimento? ¿Cómo generar deconstrucciones y construcciones de los significados de las políticas sociales a lo largo de la historia?

Estas preguntas pueden ser insumos para continuar pensando y problematizando sobre el mundo que buscamos construir, donde seguramente, la democratización de nuestras prácticas cotidianas y el reconocimiento de los derechos humanos deben de ser nuestros ejes para generar una intervención social pensada con la ciudadanía.

\section{Referencias bibliográficas}

Del Prado, Leonel (2020). La comunidad en las políticas de desarrollo social. Paraná, Argentina: Fundación La Hendija.

Díaz, Cristina; Giménez Béliveau, Verónica; Lucero, Marcelo y Uranga, Washington (Coord.) (2020). Politicas Sociales. Estrategias para construir un nuevo horizonte de futuro. Buenos Aires, Argentina, Ministerio de Desarrollo Social, CEIL-CONICET; RIPPSO; FAUATS.

Recibido: $14 / 05 / 2021$

Aceptado: 8/05/2021 